\title{
Geologist set to challenge 'creationism' verdict
}

[SYDNEY] The conflict about the competing claims of evolution and the fundamentalist interpretation of the biblical account of creation is due for another burst of public attention in Australia. Last week, Ian Plimer, the geologist who lost his main legal challenge to the creationist Allen Roberts just over three weeks ago (see Nature 387, $540 ; 1997)$, lodged an appeal to the Full Bench of the Federal Court.

Plimer's lawyers will claim that Justice Ronald Sackville erred in deciding that Roberts had not acted in trade or commerce in raising funds for "archaeological research" on the supposed remains of Noah's Ark in Turkey.

A campaign to help Plimer with his crippling legal costs has also been launched at a public meeting at which the Anglican Arch- bishop of Adelaide spoke in his support. Plimer, a former Australian Humanist of the Year, has been campaigning against the teaching of so-called "creation science" in schools.

This week, the world's oldest association of geologists, the UK Geological Society, announced it had made Plimer an Honorary Fellow "for his courageous stand against 'creation science'”. Richard Selley of Imperial College, London, writes: "Most geologists ignore creationists, and do not believe that it is worth joining them in serious debate. This is an extremely dangerous attitude and we are already seeing the price that must be paid by adopting it both in the USA and Australia. Professor Plimer is a man of enormous courage, who has put his money where his mouth is."

PeterPockley

\section{South African museums' status 'at risk'}

[CAPE TOWN] Biologists at two South African museums are disturbed at government plans to downgrade their institutions from national to provincial status, which they fear could threaten the survival of their collections.

Earlier this year, the Department of Arts, Culture, Science and Technology decided to implement proposals by a 1995 task force to group most of the country's 18 national museums into two institutions from April 1998. This would create two national museums, one in each of the twin capitals of Pretoria and Cape Town.

But some institutions will not be included. In particular, both Natal Museum and the National Museum in Bloemfontein will be downgraded to provincial status, and will in future be funded by their respective provincial governments. The KwaZulu-Natal government, which will be responsible for funding Natal Museum, cut its museum service operating budget this year by more than 51 per cent.

Both museums hold collections of scientific interest. The Natal Museum's mollusc collection, in particular, is by far the largest both on the African continent and on the entire Indian Ocean rim. George Branch, professor of zoology at the University of Cape Town, says: "There is no doubt that this is a national resource which all marine ecologists in the country use for reference purposes. If its funding is reduced, then we risk losing both the collection itself, which requires maintenance, and the taxonomic expertise of those who work on it."

Two researchers at the Natal Museum, Dick Kilburn and Dai Herbert, have

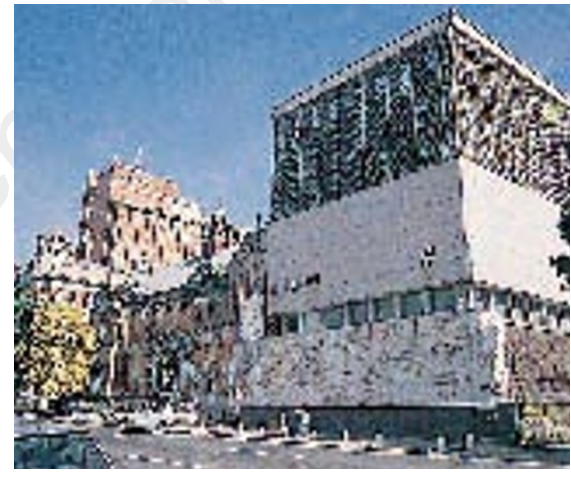

Natal's museum: mecca for molluscs.

requested colleagues worldwide to appeal against the decision, which they claim has been taken without any assessment of the significance of the museum's collections.

In fact, a review committee set up by the Department of Arts, Culture, Science and Technology last year to review the status of the country's museums did not assess the geographical representativeness of the collections at either of the two museums whose status is to be downgraded (see Nature 384, 15; 1996). Nor did it make such an assessment of the two natural history museums that will be incorporated into the new national museums, the South African Museum in Cape Town and the Transvaal Museum in Pretoria.

The fate of the fifth natural history museum with national status, the J. L. B. Smith Institute of Ichthyology in Grahamstown, appears undecided. Its collection of 750,000 fish specimens is widely regarded as being of national importance.

\section{Competition is the spur for German research centres}

[MUNICH] The Helmholtz Society (HGF), an umbrella organization that oversees Germany's 16 national research centres, is to set up a system of 'strategy funds' worth DM150 million (US $\$ 87$ million) for which the centres will have to apply competitively.

HGF centres are financed jointly by the federal government ( 90 per cent) and the host state (Land, 10 per cent), and have a total annual budget of about DM3 billion. In future, each centre will have to contribute 5 per cent of its institutional budget, which covers running costs, investment costs and salaries, to the new funds.

This money will be redistributed through competition. Centres can apply for research projects worth upwards of DM10 million, limited to three years. In the first round, the centres must submit applications by next January to a senate committee of six scientific and six industrial members. Proposals will then be reviewed by a scientific panel that will include foreign members. Germany's main research grant-giving body, the Deutsche Forschungsgemeinschaft, is to support the committee in its choice of referees. The HGF senate, which consists of members from the political, scientific and industrial arenas, will make its final decisions next spring, and the chosen projects will start in July 1998.

Areas likely to be covered by the new funds include bioinformatics, environmental technologies and superconductors. In addition, from next year they will be used to finance HGF's Young Scientists Programme. The society will advertise jobs for around 500 young scientists in the next three years.

After a meeting last week with Joachim Treusch, the HGF president, Germany's research minister, Jürgen Rüttgers, promised support for the new plans.

Scientists at HGF have broadly welcomed the competition plans, but they are concerned that large interdisciplinary HGF centres with a strong base in applied research, such as the Forschungszentrum Jülich, are likely to benefit most because of their strong links with industry.

"We certainly don't shy away from competition", says Max Tilzer, director of the AlfredWegener-Institut for Polar and Marine Research in Bremerhaven. "But to make sure we get a fair chance, industrial and basic research projects have to be treated equally."

Treusch, who is director of both the Helmholtz Society and the Forschungszentrum Jülich, dismisses the fear that, in accordance with prevailing political opinion, basic research could fall behind. "HGF centres of excellence should have hopes instead of fears," he says.

QuirinSchiermeir 